In Barry Wellman and Caroline Haythornthwaite (Eds.) (2002). The Internet and Everyday Life. Oxford, UK: Blackwell. Forthcoming.

\title{
The Not So Global Village of Netville ${ }^{1}$
}

\author{
Keith N. Hampton \\ Department of Urban Studies and Planning \\ Massachusetts Institute of Technology
}

\author{
Barry Wellman \\ Department of Sociology \\ University of Toronto
}

November 14, 2001

\begin{abstract}
We examine the experience of the residents of Netville, a suburban neighborhood with access to some of the most advanced new communication technologies available, and how this technology affected the amount of contact and support exchanged with members of their distant social networks. Focusing exclusively on friends and relatives external to the neighborhood of Netville, "community" is treated as relations that provide a sense of belonging rather than as a group of people living near each other. Computer-mediated communication (CMC) is treated as one of several means of communication used in the maintenance of social networks. Contrary to expectations that the Internet encourages a "global village," those ties that previously were "just out of reach" geographically, experience the greatest increase in contact and support as a result of access to CMC.
\end{abstract}

\footnotetext{
${ }^{1}$ Authors' Notes: This research was supported by the Social Science and Humanities Research Council of Canada IBM's Institute of Knowledge Management, Metel Networks, and Communication and Information Technologies Ontario. At the University of Toronto, we have benefitted from our involvements with the Centre for Urban and Community Studies, the Department of Sociology, and the Knowledge Media Design Institute. We thank a host of people for their comments, assistance, and support. At the University of Toronto: Dean Behrens, Nadia Bello, Sivan Bomze, Bonnie Erickson, Todd Irvine, Kristine Klement, Emmanuel Koku, Alexandra Marin, Dolly Mehra, Nancy Nazer, Christien Perez, Grace Ramirez, Janet Salaff, Richard Stren, Carlton Thorne, and Jeannette Wright. Others: Ross Barclay, Donald Berkowitz, Damien De Shane-Gill, Jerome Durlak, Herbert Gans, Paul Hoffert, Timothy Hollett, Thomas Jurenka, Marc Smith, Liane Sullivan, and Richard Valentine. Our greatest debt is to the residents of Netville who have given their time and patience, allowing us into their homes and answering many questions. Portions of this work are reprinted from Keith Hampton's doctoral dissertation, and previously published under the title "Long Distance Community in the Network Society: Contact and Support Beyond Netville", American Behavioral Scientist 45(3), 476-495, (C) Copyright Sage Publications 2001. For more papers on the Netville project please visit www.mysocialnetwork.net and www.chass.utoronto.ca/ wellman.
} 


\section{REDEFINING COMMUNITY IN A NETWORK SOCIETY}

Early urban ethnographies of the mid twentieth century played a major role in defining the sociological treatment of "community" (see Anderson 1978; Whyte 1943; S. D. Clark 1966; Gans 1962; 1967). For the most part a "community study" still refers to the study of neighborhoods. Yet most of the social support, and much of the information and resources that people require to function in their day-to-day lives comes from sources outside of the local setting (Fischer, 1982; Wellman, Carrington and Hall, 1988). Social network analysts and others have long suggested that the social aspect of community should be emphasized over the spatial (Fischer, 1982; Wellman, 1999). Indeed, "community without propinquity" is hardly a new concept, but it is one that is often neglected (Webber, 1963). Only with recent innovations in communication technology - the growth of the Internet - has there been widespread recognition by the public, the media, and indeed, scholars that supportive social relations exist at a distance (Rheingold, 2000).

The creation of a whole new type of community, the "virtual community," has done much to highlight the geographic dispersion of social ties. Yet the study of virtual communities has largely maintained the traditional framing of "community" as something that is physically bounded, but by geographies of bites and bytes rather than by streets and alleyways. Online relationships are treated as entities in themselves as if existing social networks and existing means of communication did not exist (see the review in Wellman and Gulia, 1998.).

Community is best seen as a network - not as a local group. We are not members of a society which operates in "little-boxes," dealing only with fellow members of the few groups to which we belong: at home, in our neighborhood, workplaces, or in cyberspace (Wellman and Hampton, 1999). Rather, each person has his/her own "personal community" of kinship, friendship, neighboring and workmate ties. People use multiple methods of communication in maintaining ties with community 
members: direct in-person contact, telephone, postal mail, and more recently fax, email, chats, and email discussion groups. This social definition of "community" emphasizes supportive, sociable, relations that provide a sense of belonging rather than a group of people living near to each other (Wellman, 1999). This approach implies that computer-mediated communication (CMC) has not introduced a new geography to community; it has introduced a new means of social contact with the potential to affect many aspects of personal communities.

This paper examines the experience of the residents of "Netville,"2 a suburban neighborhood with access to some of the most advanced new communication technologies available, and how this technology affected contact and support stretching beyond Netville to the residents' personal communities.

\section{WIRED TIES AND THE FATE OF COMMUNITY}

Unlike the almost universal earlier fear that technologies such as the automobile and television would harm community (Stein, 1960), the debate about the Internet comes in two flavors (Wellman and Gulia, 1999). Enthusiasts hail the Internet's potential for making connections without regard to race, creed, gender or geography. As Phil Patton early proclaimed: "Computer-mediated communication ... will do by way of electronic pathways what cement roads were unable to do, namely connect us rather than atomize us, put us at the controls of a 'vehicle' and yet not detach us from the rest of the world" (1986: 20). By contrast, dystopians suggest that the lure of new communication technologies withdraws people from in-person contact and lures them away from their families and communities (Kraut, et al., 1998; Nie and Erbring, 2000; Nie, 2002). They worry that meaningful contact will wither without the full bandwidth provided by in-person, in-the-flesh

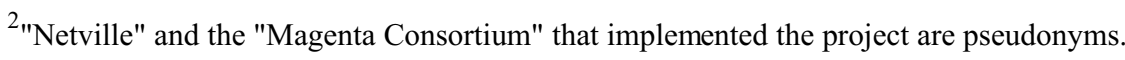


contact. As Texas commentator Jim Hightower warned over the ABC radio network: "While all this razzle-dazzle connects us electronically, it disconnects us from each other, having us 'interfacing' more with computers and TV screens than looking in the face of our fellow human beings" (quoted in Fox, 1995, p. 12).

Yet, several scenarios are possible. Indeed, each scenario may happen to different people or to the same person at different times. In an "information society" where work, leisure, and social ties may all be maintained from a "smart home," people could reject the need for social relationships based on physical location. They might find community online, or not at all, rather than on street corners or while visiting friends and relatives. In such a scenario, new communication technologies may advance the home as a center for services that encourage a shift toward greater homecenteredness and privatization (Wellman, 2000). At the same time the location of the technology inside the home facilitates access to local relationships, suggesting that domestic relations may flourish, possibly at the expense of more distant ties.

Our research has been guided by a desire to integrate the study of community offline and online. We are interested in the totality of relationships in community ties and not just in behavior in one communication medium or locale. In this we differ from studies of "virtual community" that only look at relationships online (e.g. Baym, 1997; O'Brien 1998) and from traditional sociological studies of in-person, neighborhood-based communities (e.g., Gans 196; Campbell and Lee 1999). The former can overemphasize the importance of computer-only ties, while the latter do not take into account the importance of transportation and communication in connecting community members over a distance. Unlike many studies of $\mathrm{CMC}$ that observe undergraduates in laboratory experiments (reviewed in Sproull and Kiesler, 1991; Walther, Anderson and Park, 1994), we study people in real 
settings. We focus here on the effect of new communication technologies on the residents of the wired neighborhood of Netville.

\section{THE SOCIAL AFFORDANCES OF THE INTERNET ${ }^{3}$}

Pre-Internet advances in transportation and communication technology partially emancipated community from its spatial confines. The cost of mobility and of social contact have decreased with the advent of technologies such as the train, automobile, airplane, and telephone (Hawley, 1986). People decentralized their active social ties as the financial and temporal costs of transcending space decreased. $\mathrm{CMC}$ - in the form of email, chat groups and instant messaging - introduces new means of communication with friends and relatives at a distance. The Internet has the capacity to foster global communities, in which ties might flourish without the constraints of spatial distance. On the Internet, neighbors across the street are no closer than best friends across the ocean. In practice, the shrinking of the map of the world is unlikely to go so far. Most ties probably function through the interplay of online and offline interactions. Hence, CMC should lessen, but not eliminate, the constraints of distance on maintaining personal communities.

With the telephone, the cost of contact increases with physical distance. By contrast, the cost of contact with $\mathrm{CMC}$ does not vary with distance but is based on a flat fee, along with access to a personal computer and the Internet. For most, the decision to purchase a home computer has been based on a desire to expand educational or work opportunities and not directly out of a need to maintain contact with distant network members (Ekos, 1998). As a result, the ability to use CMC as a form of contact is largely a by-product of a financial investment in other activities.

\footnotetext{
3 Affordances" is a term used in the study of human computer interaction (Gaver, 1996; Norman, 1999). Erin Bradner (2000), writing for computer scientists, coined the term "social affordances" to emphasize the social as well as individual possibilities of computer networks..
} 
In addition to reducing the financial cost of social contact, specific forms of $\mathrm{CMC}$, such as email, provide temporal freedom. Asynchronous email means that both parties do not have to be present for contact to take place. Analogous to the traditional paper letter, email can be composed without the immediate participation of the receiving party. Those with free, high-speed, always-on Internet access, that was available to the residents of Netville are even better situated to experience increased social contact with network members. They can send messages whenever the urge hits them, without waiting to boot up the computer, dial the Internet, or worry about interfering with telephone calls. They can quickly send and receive pictures, audio messages, and email. As temporal flexibility becomes more important with complex, individualized daily lives (Wellman, 2001), CMC should improve the ability of contact to take place for local as well as distant network members ${ }^{4}$.

What kinds of community does this type of technology afford? It is time to move from speculation to evidence. This chapter tests the hypotheses that:

- Living in a wired neighborhood with access to free, high-speed, always-on Internet access increases social contact with distant network members.

- Those ties located at the greatest distance will experience the greatest increase in contact as a result of Internet access.

Previous studies have demonstrated that $\mathrm{CMC}$ can be used for the exchange of non-instrumental support, such as companionship and emotional aid (Haythornthwaite and Wellman, 1998). In this way $\mathrm{CMC}$ is similar to the telephone in its ability to participate in the exchange of social support regardless of physical distance. However, instrumental aid - such as lending household items and providing child care - relies more on physical access and is more appropriately exchanged with physically-available network members (Wellman and Wortley, 1990, Wellman and Frank 2001). For

\footnotetext{
${ }^{4}$ As it takes at least two tangle, the contact of Netville residents was limited because many of their friends and relatives who lived elsewhere had much slower and more sporadic connections.
} 
ties in close proximity, the introduction of CMC may help facilitate the delivery of aid but is likely limited to supplementing existing means of communication. At best $\mathrm{CMC}$ will contribute to a modest increase in support exchanged with nearby ties. ${ }^{5}$

The more physically distant ties are also unlikely to experience a significant increase in the exchange of support as a result of CMC. Regardless of the means of communication, distance between network members makes it difficult to provide many goods and services. Support that depends less on contact to be effective - such as financial aid, companionship, and emotional aid are more likely to benefit from $\mathrm{CMC}$ between distant network members.

When $\mathrm{CMC}$ is adopted, it is likely to afford the greatest increase in support among mid-range ties located somewhere between the most distant network members and those who live nearby. CMC, particularly email, should facilitate coordination with mid-range ties, increase awareness of network members' social capital, and increase the amount and breadth of support exchanged. Network members within this mid-range can provide non-instrumental aid that does not rely on inperson contact. With some coordination and effort, they can also provide instrumental aid. The reduced cost and temporal flexibility of email reduces previous barriers to obtaining such support from mid-range network members. We would therefore expect the greatest increase in the exchange of overall support to occur with those who were previously “just out of reach”. We hypothesize that:

- Moving into a wired neighborhood with free, high-speed, always-on Internet access increases overall levels of support exchanged with network members. In particular, mid-range ties (50-500 $\mathrm{km})$ will experience the greatest increase in the exchange of overall support.

\footnotetext{
${ }^{5}$ Neighborhood ties are an exception in Netville and are treated as a special case in Hampton, 2001 and a Hampton and Wellman article, 2002.
} 


\section{STUDYING NETVILLE ${ }^{6}$}

\section{Netville}

The evolving nature of the Internet makes it a moving research target. Almost all research can only describe what has been the situation, rather than what is now or what will soon be. We have been blessed with a window into the future by having spent several years studying "Netville": a leading-edge "wired suburb" filled with a series of new information and communication technologies that are not yet publicly available. The widespread use of such technology in Netville makes it an excellent setting to investigate the effects of future forms of $\mathrm{CMC}$ on community.

Netville is a newly-built development of approximately 109 medium-priced detached homes in a rapidly growing, outer suburb of Toronto. Most homes have three or four bedrooms plus a study: 2,000 square feet on a 40 foot lot. In its appearance Netville is nearly identical to most other suburban developments in the Toronto area. Its distinguishing feature is that it is one of the few developments in North America where all of the homes were equipped from the start with a series of advanced communication technologies supplied across a broadband high-speed local network. Users could reliably expect network speeds of at least $10 \mathrm{Mbps}$, more than ten times faster than other commercially available "high"7 Internet systems (i.e., telephone DSL and cable modem services), and more than 300 times faster than dial-up telephone connections. For two years, the local network provided residents with high speed Internet access (including electronic mail and Web surfing), computer-desktop videophone, an online jukebox, entertainment applications, online health services,

\footnotetext{
${ }^{6}$ For more details, see Hampton (2001b), Hampton (2001a), Hampton (1999), and Hampton and Wellman (1999).

7"Always on" Internet access refers to a property of most high-speed Internet services which allows users to be connected to the Internet whenever the computer is turned on, without performing any special tasks, manually starting any additional programs, or "dialing up" to the Internet.
} 
and local discussion forums. In exchange for free access to these advanced services, Netville residents

agreed to be studied by the corporate and scholarly members of the "Magenta Consortium", the organization responsible for developing Netville's local network. ${ }^{8}$ Approximately 60 percent of Netville homes participated in the high bandwidth trial and had access to the network for up to two years. The other 40 percent of households, for various organizational reasons internal to the Magenta Consortium, were never connected to the network despite assurances at the time residents purchased their homes that they would be. ${ }^{9}$ Those households not connected to the local network provide a convenient, quasi-random comparison group for studying the effects of computer-mediated communication.

Wired and non-wired Netville residents were similar in terms of age, education and family status (Hampton, 2001b). Residents were largely middle class, English-speaking, and married. More than half of all couples had children living at home when they moved into the community, and as with many new suburbs, a baby boom happened soon after moving in. Although most residents were white, an appreciable minority were racial and ethnic minorities. About half had completed a university degree. Residents worked at such jobs as technician, teacher, and police officer. Their median household income in 1997 was C\$75,000 (US\$50,000). Netville residents were as likely to have a televison, a VCR, cable TV, a home computer and home Internet access as other Canadian's of similar socioeconomic status (Hampton, 2001b). While the decision of some to purchase a home in Netville was motivated by the technology available, only 21 percent of home purchasers identified Netville's "information services" as one of the top three factors in their purchasing decision.

\footnotetext{
${ }^{8}$ This agreement was only lightly enforced and often forgotten by the residents. No resident was ever denied service for refusing to participate, and no data were ever collected without the residents' knowledge.

${ }^{9}$ Magenta never clarified why some Netville homes were connected and others were not. The two most likely causes were the Consortium's limited access to resources for completing home installations, and miscommunications with the housing developer in identifying homes that had been occupied.
} 
As technology developed and fashions changed, the telecommunications company responsible for Netville's local network decided that the hybrid fibre coaxial technology used in the development was not the future of residential Internet services. They terminated the field trial early in 1999 to the dismay of the residents (Hampton, 2002).

\section{Research Design}

Our research objectives led us to gather information about residents' community ties online and offline, globally and locally. These included: relations within Netville (see Hampton, 2001b; Hampton and Wellman, 2002), personal networks extending well beyond Netville (the subject of this chapter), civic involvement, and attitudes toward community, technology and society. We used several research methods, principally ethnographic fieldwork and a cross-sectional survey.

Ethnography: In April 1997, one of us, Keith Hampton, began participating in local activities. Hampton moved into Netville in October 1997 (living in a resident's basement apartment), staying until August 1999. Given the widespread public interest in Netville, residents were not surprised about his research activity and incorporated him into the neighborhood. Hampton worked from home, participated in online activities, attended all possible local meetings (formal and informal), walked the neighborhood chatting, and did ethnographic participant-observation. Like other residents, he relied on the high-speed network to maintain contact with social network members living outside of Netville. His daily experiences and observations provided detailed information about how residents used the available technology, their domestic and neighborhood relations, and how they used time and local space. Insights gained through observation and interactions were instrumental in developing the survey and in establishing trust with local residents.

Survey: The survey was first administered to those moving into Netville in April 1998 and was expanded to include existing wired and non-wired residents in September 1998. The survey obtained 
information on geographic perception, personal and neighborhood networks, neighboring, community alienation, social trust, work, experience with technology, time-use, and basic demographics. We tried to learn the extent to which Netville residents' personal networks were abundant, strong, solidary, and local. Our attempt to collect detailed information on residents' closest social ties was met with mixed success as a result of Magenta's decision to end the technology trial and problems in our use of computer-assisted interviewing (see Hampton, 1999). As a result, while recognizing that different types of ties (friends, relatives, etc.) and ties of different strength are likely to provide different types of aid and support, this chapter does not include an analysis of specific types of ties or forms of support. Instead we focus exclusively on changes in social contact and exchange of support with friends and relatives at various distances. Noticeably absent from this chapter is a full review of Netville residents' neighborhood ties, explored briefly in the conclusion of this paper and more extensively in Hampton (2001b), Hampton (2002) and Hampton and Wellman (2002).

\section{Measuring Social Contact and Support}

We report here on change in contact and support with non-local friends and relatives living outside Netville. ${ }^{10}$ We asked 18 questions about change in support and contact with network members living at the distances of (1) less than 50 kilometers (excluding neighborhood ties), (2) 50 to $500 \mathrm{~km}$, and (3) greater than $500 \mathrm{~km}$ in comparison to one year before their move to Netville. Participants were asked to indicate on a five-point scale from -2 (much less) to +2 (much more) how

\footnotetext{
${ }^{10}$ Some caution should be taken in the interpretation of this data, Participants were not asked to indicate if they had ties at the specified distances both pre and post move. Participants who responded that they did not have social ties at a given distance were coded as having the "same" level of contact or support pre and post move. Participants may have experienced no change in contact as a result of not having ties at the specified distance, or report change as a result of not having network members at the specified distance either pre-move or post-move. However, there is no indication that this limitation in the data should significantly affect the results as they are presented here.
} 
their overall levels of contact and support exchanged with friends and relatives had changed. The

18 ordinal variables were combined into eight scales that document: ${ }^{11}$

1) Change in social contact with all social ties regardless of distance

2) Change in support exchanged with all social ties regardless of distance

3) Change in social contact with ties outside Netville but within $50 \mathrm{~km}$

4) Change in support exchanged with ties outside Netville but within $50 \mathrm{~km}$

5) Change in social contact with mid-range $(50-500 \mathrm{~km})$ social ties

6) Change in social support exchanged with mid-range $(50-500 \mathrm{~km})$ social ties

7) Change in social contact with ties more than $500 \mathrm{~km}$ away

8) Change in support exchanged with ties more than $500 \mathrm{~km}$ away.

To test hypotheses of how living "wired" in Netville, with access to the local high-speed network, affects contact and support exchanged with social network members, the distribution and mean scores for wired and non-wired participants are compared for change in social contact and support (1) regardless of distance, and with network members living at (2) less than $50 \mathrm{~km}$ (which includes Toronto, but excludes immediate neighbors), (3) 50-500 km, and (4) more than $500 \mathrm{~km}$.

Social contact and support scales are dependent variables in regressions that include the independent variables of wired status (connected or not connected to Netville's high-speed network) and control variables for gender, age, years of education and length of residence (the length of time participants had lived in Netville at the time they were interviewed). The rationale for inclusion of the control variables are:

\footnotetext{
${ }^{11}$ Cronbach's alpha, a measure of internal consistency and reliability among scale items shows that all scales (except one) have a satisfactory alpha above 0.7 . The exception, the scale for change in contact with non-neighborhood network members living within $50 \mathrm{~km}$, is retained because the significant correlation of 0.32 of the two variables comprising it validates the underlying consideration in scale construction that participants respond consistently across scale constructs.
} 
1. Gender: Women may be more likely than men to experience a change in social contact or support as a result of their role in maintaining the majority of household ties (Wellman 1992; Wright 1989).

2. Age: Age may contribute to network stability and reduce the likelihood of experiencing change in social contact or support.

3. Education: Education contributes to greater social and financial capital which may help in the maintenance of social contact and support networks (Putnam, 2000).

4. Length of Residence: Moving may disrupt communication with network members. Length of residence in Netville is included to control for the possibility that early movers may report a drop in social contact and support in comparison to those who have had time to settle into their new home.

\section{SOCIAL CONTACT AND SOCIAL SUPPORT}

\section{Overall Changes}

Contact: Compared to one year before moving to Netville, 41 percent of Netville residents report a drop in social contact with friends and relatives, 32 percent report no change, and 28 percent report an increase. Yet wired residents had significantly more contact than non-wired: 68 percent of wired residents reported that their overall level of social contact either increased or remained the same as compared with only 45 percent of non-wired residents (Figure 1). On average, non-wired residents report a drop in contact and wired residents report almost no change in social contact compared to a year before their move (Table 1). Holding other factors constant, the negative intercept coefficient in Table 2 indicates that Netville residents generally experienced a drop in contact as a result of their move. This is consistent with the observations of S. D. Clark (1966) and Herbert Gans (1967) who observed a similar loss of social contact among new suburban dwellers. 
Although moving to a new suburban neighborhood generally decreased the contact of Netville residents with friends and relatives, access to the high-speed network helped wired residents to maintain contact. Both personal attributes and high-speed access affect contact with social network members. Being wired, better educated, and older positively affect change in overall contact (Table 2). Being connected to the local network has the same effect on boosting social contact as four more years of education or nearly thirteen years of increased age. Among younger residents with fewer years of formal education, wired status is particularly important in helping maintain contact at premove levels.

Support: Fully 79 percent of wired Netville residents report the same or more support after moving as compared to only 50 percent of non-wired residents (Figure 2). As with social contact, wired residents on average have maintained support near pre-move levels while non-wired residents report significantly less support (Table 3). Controlling for other factors, those who moved into Netville report an overall decrease in support exchanged with network members across all distances (Figure 3.7). Living in Netville and being connected to the local high-speed network reverses this trend. On average, non-wired residents report a moderate drop in support while wired residents have been able to maintain support slightly above pre-move levels. Indeed, being wired is the only variable that is significantly associated with changes in the exchange of support (Table 4).

\section{Ties Living Within 50 Kilometers (excluding neighbors)}

Contact: We have hypothesized that as distance to ties increases, access to CMC will facilitate increased contact. At this distance, 65 percent of wired and 55 percent of non-wired residents report either no change or a small increase in contact with nearby ties (Figure 3). On average, wired and non-wired residents both experienced a minor drop in contact with ties at this distance (Table 1). While non-wired residents average a slightly greater drop in contact, analysis of variance does not 
identify a statistically significant difference between the mean scores of wired and non-wired residents. Controlling for gender, age, education and length of residence fails to reveal an effect of wired status on contact with network members living within $50 \mathrm{~km}$, but not within Netville (Table 2). Years of education is the only significant variable predicting contact. As in the previous analysis, the act of moving contributed to a loss of contact for all Netville residents. While those with at least seventeen years of education (more than a Bachelor's degree) have been able to maintain contact at pre-move levels, all other residents experienced a drop in social contact with non-neighborhood ties living within $50 \mathrm{~km}$ compared to a year before their move.

In sum, being wired neither increases or decreases social contact with non-neighborhood network members living within $50 \mathrm{~km}$. Much contact with these network members continues to use established means of communication, such as the telephone and in-person meetings. Moving to Netville and accessing its high-speed local network does not appreciably change the amount of contact.

Support: Wired residents (82 percent) are more likely than non-wired (75 percent) to report either a small increase or no change in support from nearby network members (Figure 4). On average, non-wired residents report almost no change in social support while wired residents report a very slight increase compared to a year before their move (Table 3). The mean scores for wired and non-wired residents are not statistically different (Table 3), nor does any other variable predict to changes in support with nearby network members (Table 4). As hypothesized there is no effect of $\mathrm{CMC}$ on the exchange of support with non-neighborhood ties living within $50 \mathrm{~km}$.

\section{Mid-Range Ties (50-500 Kilometers Away)}

Contact: When network members live 50 to $500 \mathrm{~km}$ away, they are at a distance where telephone and in-person contact become more costly and difficult, and where less costly CMC may be used 
more. Controlling for other factors, Netville residents had less contact with mid-range network members as a result of their move (negative intercept in Table 2). Unlike nearby ties, wired residents were able to maintain contact with mid-range ties while non-wired residents were not (Tables 1 and 2). Indeed, being wired is the only significant variable for change in contact with mid-range ties. The majority (62 percent) of wired residents report no change in contact, 18 percent report a decrease and 21 percent report an increase. By contrast, although 50 percent of non-wired residents report no change, fully 45 percent report some level of lost contact, and only 5 percent report increased contact (Figure 5).

Support: Mid-range ties should experience the greatest increase in support as a result of being wired. They are far enough apart that CMC is especially useful for communication, but they are near enough to each other that the delivery of material aid (as well as emotional aid) can be accomplished without great strain. Being wired is the only variable significantly associated with changes in the level of support from mid-range ties (Table 4). ${ }^{12}$ Although mid-range support in Netville did not increase with being wired, being wired has enabled residents to maintain pre-move levels of supportiveness with mid-range ties. By contrast, residents who were not wired exchange significantly less support after moving (Tables 3 and 4). Fully 82 percent of wired residents report no change in support after moving, only 6 percent reported a decrease, and 12 percent an increase (Figure 6). By contrast, only 40 percent of the non-wired residents reported no change in support, the majority (55 percent) reported a decrease, and only 5 percent an increase.

As with the previous analysis, moving to Netville introduced a barrier to the exchange of support with network members. However, when Netville residents became connected to the local high-speed

\footnotetext{
${ }^{12}$ The lack of variation in the support scale for wired residents suggests that some caution should be taken in interpreting the results of the regression analysis.
} 
network, they were able to overcome after-move barriers to the exchange of support with network members living 50 to $500 \mathrm{~km}$ away.

\section{Distant Ties (More Than 500 Kilometers Away)}

Contact: Social contact by conventional means (i.e., telephone, in-person meetings) is expensive with network members who live more than $500 \mathrm{~km}$ away. To support the hypothesis that access to Netville's local network is most successful in increasing contact with the most distant social ties, wired residents should report an increase in contact relative to non-wired residents of greater magnitude than for their mid-range ties.

As expected, wired residents have been better able than the non-wired to maintain contact with network members living far away (Table 1, Figure 7). By contrast, non-wired residents have not been able to maintain pre-move levels of contact. This is the only measure of social contact where the wired have not only been able to maintain contact at pre-move levels but on average report an increase over pre-move levels. Being wired and being older both significantly affect contact at this distance (Table 2).$^{13}$ Those over the age of 38 and non-wired, and those over the age of 25 and wired have been able to maintain contact with distant network members at pre-move levels. Only one wired resident reports a decrease in social contact, while 74 percent report no change and 24 percent report an increase (Figure 7). By contrast, 35 percent of non-wired report a decrease in contact, 55 percent report no change, and only 10 percent an increase. The distribution of the social contact scale follows the trend of the previous two analyses: The greater the distance between Netville and network members, the more likely that Netvillers will not experience any change in social contact.

\footnotetext{
13 The small amount of variation in the contact scale for wired residents suggests that some caution should be taken in interpreting the results of the regression analysis. Regression analysis with a dependent variable that is extremely light-tailed, as is the scale for change in support at more than $500 \mathrm{~km}$, violates the assumption of equal variance. The results of the regression reported in Table 4 for ties at this distance should be interpreted with caution.
} 
Support: By contrast to our expectation of increased contact, we did not expect that being wired would increase support exchanged with the most distant social ties. The lack of easy physical access makes distant network members ill-suited for exchanging tangible goods and services. Access to new methods of communication, provided through high-speed Internet access, may at best afford a minor increase in the exchange of intangible, non-material support, such as emotional aid.

In practice, most wired and non-wired residents report no change after moving in the supportiveness of their most distant network members. Yet there are significant differences between the wired and non-wired residents (Table 3). Once again, the Internet enables almost all wired residents (94 percent) to maintain support at pre-move levels (Figure 8). Only 3 percent have experienced an increase and 3 percent a decrease. By contrast, a significant minority ( 30 percent) of non-wired residents have experienced a drop in support with their most distant social ties, 65 percent of non-wired residents report no change, and only 5 percent an increase. Being wired is the only variable which affects changes in level of support with distant ties (Table 4).

\section{DISCUSSION}

\section{The Not So Global Village of Netville}

Moving to Netville, a new suburban neighborhood, reduced contact and support with friends and relatives. The move to a new home and neighborhood is itself stressful, former neighbors are no longer at hand, and with the move to an outer suburb, distance may play a role in reducing contact and the exchange of support with network members (Gans, 1967; Clark, 1966). Yet Netville residents with access to a free, high-speed, always-on computer network have been more successful than the non-wired in maintaining contact and exchanging support with friends and relatives.

Wired residents maintained higher levels of contact as a result of $\mathrm{CMC}$ and were able to maintain contact at pre-move levels with network members living more than $50 \mathrm{~km}$ away. By 
contrast, non-wired Netville residents experienced a drop in contact with social ties at all distances in comparison to a year before their move.

As hypothesized, living in a wired neighborhood with access to free, high-speed, always on, Internet access affords more social contact with distant network members. Being wired affords as much contact at mid-range than at long distance. Comparing unstandardized regression coefficients at $50-500 \mathrm{~km}$ and $500+\mathrm{km}$ does not confirm the expectation that as distance increases, CMC facilitates greater contact (Table 2). Those who are wired experienced nearly the same change in social contact with ties beyond $500 \mathrm{~km}$ as they did with ties between $50-500 \mathrm{~km}$. The slightly smaller regression coefficient for the effect of being wired on contact with ties $500+\mathrm{km}$ suggests a leveling off or even a slight drop in the effect of CMC on contact as distance increases. The slightly greater effect of being wired on contact with mid-range ties may relate to easier in-person contact and the types of support that are likely to be exchanged with ties at this distance. Frequent contact and the provision of tangible support reinforce each other (Homans, 1961; Wellman and Wortley, 1990; Wellman and Frank, 2001).

If they were not wired, Netville residents had difficulty in maintaining pre-move levels of support with network members living more than $50 \mathrm{~km}$. Wired residents maintained support at pre-move levels with ties at all distances, whereas non-wired residents had decreased support with ties more than $50 \mathrm{~km}$ away. Based on a comparison of unstandardized regression coefficients, being connected to Netville's high-speed network had nearly twice the effect on support with network members at the 50-500 km range as it did with those at more than $500 \mathrm{~km}$ (Table 4). This is consistent with the hypothesis that Netville's free, high-speed, always on, Internet access increased overall levels of support exchanged with network members, but that mid-range ties experienced the greatest increase in the exchange of support. Although the move to a new suburb depressed contact and support, Netville's local computer network helped residents maintain contact and support at pre-move levels. 
The increased connectivity of a high-speed network should increase contact and support beyond pre-existing levels in an established neighborhood. It is not that the Internet is special. Rather, the Internet is another means of communication used along with existing media, especially in-person contact and the telephone. When distance makes in-person and telephone communication difficult, CMC has the potential to fill the gap.

\section{Glocalization - CMC Fosters Contact and Support, Near and Far}

What was not explored in this paper, but is explored in detail in Hampton (2001) and Hampton and Wellman (2002), is that in Netville computer-mediated communication reached across distances both locally as well as globally. The wired residents of Netville neighbored much more extensively and intensively than their non-wired counterparts. Many local friendships and community activities developed. Although this is a usual characteristic of moving into a new suburban development (Gans, 1967), wired Netville residents neighbor much more than those who are offline. Wired Netville residents on average know the names of 25 neighbors as compared to eight for the nonwired, they talk to neighbors twice as often, and they visit in each other's homes 50 percent more often (Hampton, 2001b; Hampton and Wellman, 2002). The social ties of wired Netville residents, in particular weaker social ties, are spread more widely throughout the neighborhood. Instead of knowing just those neighbors in the few homes that surround their own, the wired residents of Netville know people down the street, around the corner and on the other side of the block.

Computer-mediated communication did not replace existing means of communication, but added it added a new form of social contact to personal networks. Within Netville, CMC increased social contact by additional means of communication. Wired Netville residents not only email and videophone with their neighbors, but they telephone them much more often (Hampton, 2001a). For neighbours to come together and act collectively often requires motivated individuals to knock on 
the doors of near strangers in order to generate grass-roots support for individual causes. In Netville CMC, combined with a dense network of local weak ties (Granovetter, 1973), facilitated collective action (Hampton, 2002). Residents organized to protest perceived housing deficiencies, and when those providing their technology announced that it would be taken away, they again organized collectively (Hampton, 2001; Hampton 2002).

On average, most North Americans have few strong ties at the neighbourhood level (Wellman 1979, 1999; Fischer 1982; Putnam 2000). Personal communities consist of networks of far-flung kinship, workplace (Wellman, Carrington and Hall, 1988) and interest group relations, and not place-based communities of geography. In Netville this was less so. The local computer network facilitated the formation of local social ties of various strengths. While the existence of diverse subcultures in the modern urban environment allows people to place similarity of interest over similarity of setting in selecting social ties (Fischer 1975, 1982), what may ultimately be lacking is an opportunity to meet and interact locally. Local institutions that do exist to promote local interaction (cafés, bars, community organizations, etc.) are in decline (Putnam, 2000; Oldenburg, [1989] 1999), and often were absent from suburban Netville. Access is equally as important as social similarity in determining the likelihood of tie formation (Feld, 1982) for the presence of neighborhood common space increases tie formation, the strength of local ties, and higher levels of community involvement (Brunson, Kuo, and Sullivan 1996). Computer-mediated communication can foster "glocalization": increased local as well as distant social contact. 


\section{Conclusion}

The blossoming of the Internet has affected the ways in which people connect with each other, eliminating the financial cost of long-distance communication, reducing the time and psychological cost of contacting near and far away people. Although some community ties function solely online, so-called "virtual communities" (Rheingold, 2000), in practice most people use whatever means are necessary to stay in contact with community members: in-person, by telephone, as well as the Internet (Wellman, Quan, Witte and Hampton, 2002). Contrary to dystopian predictions, new communication technologies do not disconnect people from communities. Computer-mediated communication reinforces existing communities, establishing contact and encouraging support where none may have existed before. 


\section{References}

Baym, N. K. (1997). Interpreting Soap Operas and Creating Community: Inside an Electronic Fan Culture. In S. Kiesler (Ed.), Culture of the Internet (pp. 103-120). Mahwah, NJ: Lawrence Erlbaum.

Bradner, E. (2000). Understanding Groupware Adoption: The Social Affordances of ComputerMediated Communication among Distributed Groups. Working Paper, Department of Information and Computer Science, University of California, Irvine, February.

Clark, S. D. (1966). The Suburban Society. Toronto: University of Toronto Press.

Ekos Research Associates (1998). Information Highway and the Canadian Communications Household. Ottawa, Canada: Ekos Research Associates.

Fischer, C. (1982). To Dwell Among Friends. Berkeley: University of California Press.

Fischer, C. (1984). The Urban Experience. Orlando: Harcourt Brace Jovanovich.

Fox, R. (1995). Newstrack. Communications of the ACM, 38 (8), 11-12.

Gans, H. (1967). The Levittowners. New York: Pantheon.

Gaver, W. (1996). Affordances for Interaction: The Social is Material for Design. Ecological Psychology, 8,111-29.

Hampton, K. N. (1999). Computer Assisted Interviewing: The Design and Application of Survey Software to the Wired Suburb Project. Bulletin de Méthode Sociologique, 62, 49-68.

Hampton, K. N. (2001a). Broadband Neighborhoods Connected Communities. In J. Jacko and A. Sears (Eds.), CHI 2001 Extended Abstracts. ACM Press.

Hampton, K. N. (2001b). Living the Wired Life in the Wired Suburb: Netville, Glocalization and Civil Society. Doctoral Dissertation, Department of Sociology, University of Toronto. Available at www.mysocialnetwork.net.

Hampton, K. N. (2002). Grieving For a Lost Network: Collective Action in a Wired Suburb. Mobilization, Forthcoming. 
Hampton, K. N., and Wellman, B. (1999). Netville Online and Offline: Observing and Surveying a Wired Suburb. American Behavioral Scientist, 43(3), 475-492.

Hampton, K. N., and Wellman, B. (2002). Neighboring in Netville: How the Internet Supports Community, Social Support and Social Capital in a Wired Suburb. City and Community 1.

Hawley, A. (1986). Human Ecology. Chicago: University of Chicago Press.

Haythornthwaite, C., and Wellman, B. (1998). Work, Friendship and Media Use for Information Exchange in a Networked Organization. Journal of the American Society for Information Science 49(12), 1101-14.

Homans, G. (1961). Social Behavior: Its Elementary Forms. New York: Harcourt Brace Jovanovich.

Kraut, R., Lundmark, V., Patterson, M., Kiesler, S., Mukopadhyay, T., and Scherlis, W. (1998). Internet paradox: A social technology that reduces social involvement and psychological wellbeing? American Psychologist, 53(9), 1017-1031.

Nie. N. (2001). Sociability, Interpersonal Relations, and the Internet: Reconciling Conflicting Findings. American Behavioral Scientist, 45, \#add page numbers

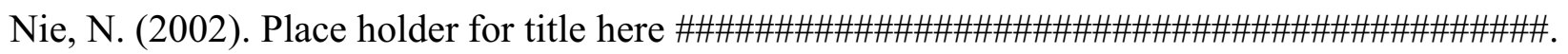
This volume.

Nie, N., and Erbring, L. (2000). Internet and Society: A Preliminary Report. Stanford, CA: Stanford Institute for the Quantitative Study of Society: Stanford University.

Norman, D. (1999). Affordance, Conventions, and Design. Interactions 6(3), 38-44.

O'Brien, J. (1998). Writing in the Body: Gender (Re)production in Online Interaction. In M. Smith \& P. Kollock (Eds.), Communities in Cyberspace (pp. 76-104). London: Routledge.

Oldenburg, R. (1999). The Great Good Places: Cafés Coffee Shops, Book Stores, Bars, Hair Salons and other Hangouts at the Heart of a Community. New York: Marlow.

Patton, P. 1986. Open Road. New York: Simon and Schuster.

Rheingold, H. (2000). The Virtual Community (revised ed.). Cambridge, MA: MIT Press. 
Smith, M., and Kollock, P., (Eds.) (1999). Communities in Cyberspace. London: Routledge.

Sproull, L. and Kiesler, S. (1991). Connections. Cambridge, MA: MIT Press.

Stein, M. (1960). The Eclipse of Community. Princeton, NJ: Princeton University Press.

Walther, J. B., Anderson, J. and Park, D. (1994). Interpersonal effects in computer-mediated interaction: a meta-analysis of social and antisocial communication. Communication Research, 21 (4): 460-487.

Wellman, B. (1997). An Electronic Group is Virtually a Social Network. In Kiesler, S. (Ed.) Culture of The Internet (pp. 179-205). Hillsdale, NJ: Lawrence Erlbaum.

Wellman, B. (Ed.) (1999). Networks in the Global Village. Boulder, CO: Westview Press.

Wellman, B. (2001). Physical Place and Cyber Place: the Rise of Networked Individualism. International Journal of Urban and Regional Research, 25: forthcoming

Wellman, B., Carrington, P., and Hall, A. (1988). Networks as Personal Communities. In Wellman, B. and Berkowitz, S.D. (Eds.).(1988). Social Structures: A Network Approach (pp.130-84) Cambridge: Cambridge University Press.

Wellman, B. and Frank, K. (2001). Network Capital in a Multi-level World: Getting Support in Personal Communities. In Lin, N., Cook, K., and Burt, R. (Eds.) Social Capital: Theory and Research (pp. 233-73). Chicago, IL: Aldine DeGruyter.

Wellman, B. and Gulia, M. (1999). Net Surfers Don't Ride Alone: Virtual Communities as Communities. In Wellman, B. (Ed.), Networks in the Global Village (pp. 331-67). Boulder, CO: Westview Press.

Wellman, B. and Leighton, B. (1979). Networks, Neighborhoods and Communities. Urban Affairs Quarterly 14: 363-90.

Wellman, B., Quan, A., Witte, J. and Hampton, K.N. (2001). Does the Internet Increase, Decrease, or Supplement Social Capital: Social Networks, Participation, and Community Commitment. American Behavioral Scientist, 45, \#add page numbers 
Wellman, B. and Tindall, D. (1993). Reach out and touch some bodies: how telephone networks connect social networks. Progress in Communication Science, 12, 63-94.

Wellman, B. and Wortley, S. (1990). Different strokes from different folks: community ties and social support. American Journal of Sociology 96, 558-88. 
Table 1. Comparison of wired and non-wired residents by mean change in contact with social ties at various distances (kilometers). ${ }^{\mathrm{a}}$

\begin{tabular}{|c|c|c|c|c|c|c|c|c|}
\hline & \multicolumn{2}{|c|}{ Overall } & \multicolumn{2}{|c|}{ Less than $50 \mathrm{~km}$} & \multicolumn{2}{|c|}{$50-500 \mathrm{~km}$} & \multicolumn{2}{|c|}{ More than $500 \mathrm{~km}$} \\
\hline & $\begin{array}{l}\text { Non } \\
\text { Wired }\end{array}$ & Wired & $\begin{array}{c}\text { Non } \\
\text { Wired }\end{array}$ & Wired & $\begin{array}{c}\text { Non } \\
\text { Wired }\end{array}$ & Wired & $\begin{array}{c}\text { Non } \\
\text { Wired }\end{array}$ & Wired \\
\hline Mean & $-0.33^{*}$ & $0.03^{*}$ & -0.28 & -0.13 & $-0.43^{*}$ & $0.03^{*}$ & $-0.30^{*}$ & $0.19^{*}$ \\
\hline SD & 0.51 & 0.38 & 0.73 & 0.58 & 0.61 & 0.56 & 0.73 & 0.46 \\
\hline Min & -1.5 & -0.67 & -2 & -1.5 & -1.5 & 1 & -2 & -0.5 \\
\hline Max & 0.33 & 1.17 & 1 & 1 & 0.5 & 1.5 & 1 & 2 \\
\hline
\end{tabular}

"Scale for mean score ranges from -2 "lot less" to +2 "lot more"; N=34 Wired, 20 Non-Wired.

Difference between means is significant at ${ }^{+} \mathrm{p}<.05{ }^{*} \mathrm{p}<.01{ }^{* *} \mathrm{p}<.001$ (ANOVA).

Table 2. Coefficients from the regression of change in social contact on wired status and other independent variables at various distances (kilometers) $(\mathrm{N}=54)$.

\begin{tabular}{|c|c|c|c|c|}
\hline $\begin{array}{c}\text { Control } \\
\text { Variables }\end{array}$ & Overall & Less than $50 \mathrm{~km}$ & $50-500 \mathrm{~km}$ & More than $500 \mathrm{~km}$ \\
\hline Wired $^{\mathrm{a}}$ & $\begin{array}{l}0.25^{+} \\
(0.26)\end{array}$ & 一 & $\begin{array}{l}0.45^{*} \\
(0.36)\end{array}$ & $\begin{array}{c}0.40^{+} \\
(0.32)\end{array}$ \\
\hline Female $^{b}$ & - & - & - & - \\
\hline Education & $\begin{array}{c}0.06^{+} \\
(0.26)\end{array}$ & $\begin{array}{c}0.10^{+} \\
(0.32)\end{array}$ & - & - \\
\hline Age & $\begin{array}{c}0.02^{+} \\
(0.25)\end{array}$ & - & - & $\begin{array}{c}0.03^{+} \\
(0.30)\end{array}$ \\
\hline Residency & 一 & - & - & - \\
\hline Intercept & $-1.73^{*}$ & $-1.74^{*}$ & $-0.43^{*}$ & $-1.16^{*}$ \\
\hline $\mathrm{R}^{2}$ & $0.26^{*}$ & $0.10^{+}$ & $0.13^{*}$ & $0.24^{* *}$ \\
\hline
\end{tabular}

Note: Numbers in parentheses are standardized coefficients $(\beta)$. Only those variables that significantly improved on the explained variance $\left(\mathrm{R}^{2}\right)$ are included in the final model; ${ }^{+} \mathrm{p}<.05{ }^{*} \mathrm{p}<.01{ }^{* *} \mathrm{p}<.001$.

${ }^{a}$ Dummy variable for wired status, reference category is wired - access to the high-speed network.

${ }^{\mathrm{b}}$ Dummy variable for gender, reference category is female. 
Table 3. Comparison of wired and non-wired residents by mean change in support exchanged with social ties at various distances (kilometers). ${ }^{\mathrm{a}}$

\begin{tabular}{|c|c|c|c|c|c|c|c|c|}
\hline & \multicolumn{2}{|c|}{ Overall } & \multicolumn{2}{|c|}{ Less than $50 \mathrm{~km}$} & \multicolumn{2}{|c|}{$50-500 \mathrm{~km}$} & \multicolumn{2}{|c|}{ More than $500 \mathrm{~km}$} \\
\hline & $\begin{array}{c}\text { Non } \\
\text { Wired } \\
\end{array}$ & Wired & $\begin{array}{c}\text { Non } \\
\text { Wired } \\
\end{array}$ & Wired & $\begin{array}{c}\text { Non } \\
\text { Wired }\end{array}$ & Wired & $\begin{array}{c}\text { Non } \\
\text { Wired } \\
\end{array}$ & Wired \\
\hline Mean & $-0.24^{*}$ & $0.05^{*}$ & 0.03 & 0.1 & $-0.51^{* *}$ & $0.04^{* *}$ & $-0.24^{*}$ & $0.01^{*}$ \\
\hline SD & 0.5 & 0.2 & 0.72 & 0.41 & 0.64 & 0.21 & 0.52 & 0.19 \\
\hline Min & -1.5 & -0.5 & -1.5 & -1 & -2 & -0.5 & -1.5 & -0.5 \\
\hline Max & 0.33 & 0.58 & 1 & 1 & 0.25 & 0.75 & 0.5 & 1 \\
\hline
\end{tabular}

a Scale for mean score ranges from -2 "lot less" to +2 "lot more"; N=34 Wired, 20 Non-Wired.

Difference between means is significant at ${ }^{+} \mathrm{p}<.05{ }^{*} \mathrm{p}<.01{ }^{* *} \mathrm{p}<.001$ (ANOVA).

Table 4. Coefficients from the regression of change in support exchanged on wired status and other independent variables at various distances (kilometers) $(\mathrm{N}=54)$.

\begin{tabular}{lcccc}
\hline \multicolumn{1}{c}{$\begin{array}{c}\text { Control } \\
\text { Variables }\end{array}$} & Overall & Less than $50 \mathrm{~km}$ & $50-500 \mathrm{~km}$ & More than $500 \mathrm{~km}$ \\
\hline Wired $^{\mathrm{a}}$ & $\begin{array}{c}0.29^{*} \\
(0.39)\end{array}$ & - & $0.55^{* *}$ & $0.25^{*}$ \\
& - & - & $(0.54)$ & $(0.33)$ \\
Female $^{\mathrm{b}}$ & - & - & - & - \\
Education & - & - & - & - \\
Age & - & - & - & - \\
Residency & - & - & $-0.51^{* *}$ & $-0.24^{*}$ \\
Intercept & $-0.24^{*}$ & - & $0.29^{* *}$ & $0.11^{*}$ \\
$\mathrm{R}^{2}$ & $0.15^{*}$ & - & - & - \\
\hline
\end{tabular}

Note: Numbers in parentheses are standardized coefficients. Only those variables that significantly improved on the explained variance $\left(\mathrm{R}^{2}\right)$ are included in the final model; ${ }^{+} \mathrm{p}<.05{ }^{*} \mathrm{p}<.01^{* *} \mathrm{p}<.001$.

${ }^{a}$ Dummy variable for wired status, reference category is wired - access to the high-speed network.

${ }^{b}$ Dummy variable for gender, reference category is female. 

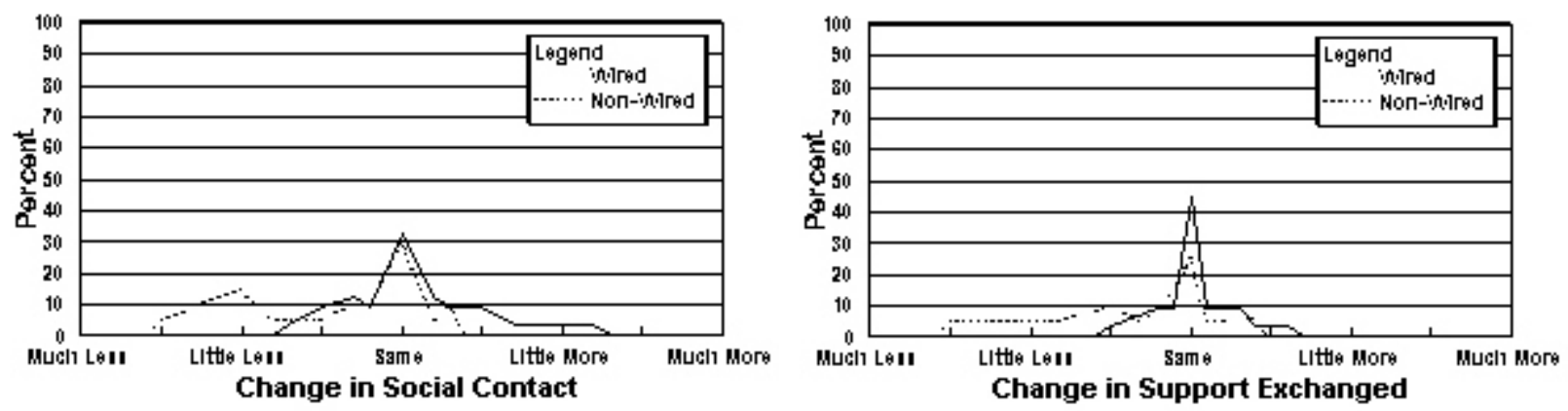

Figure 1. Overall change in social contact.

Figure 2. Overall change in social support.
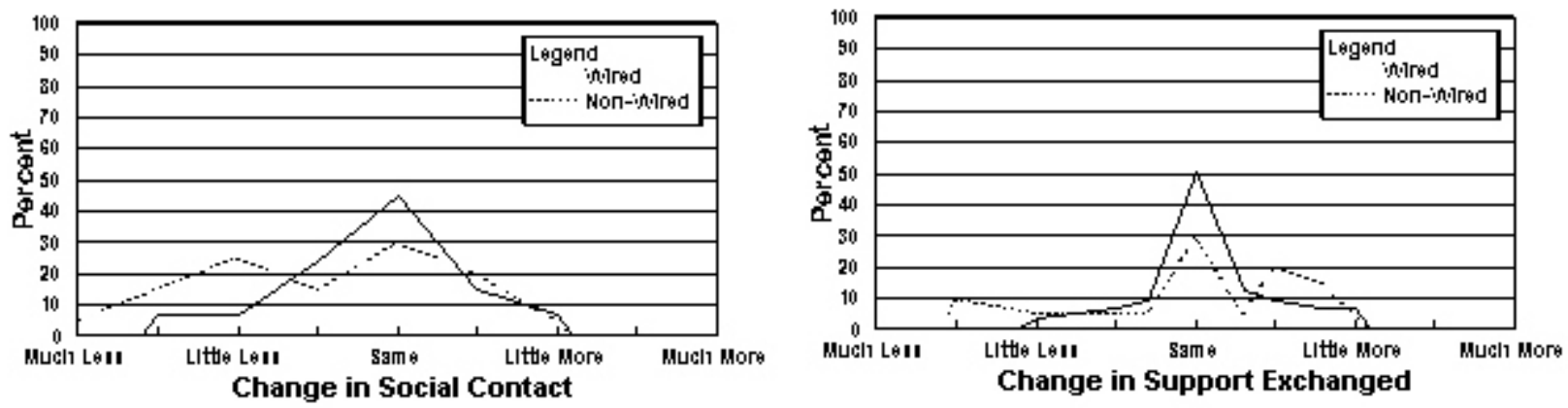

Figure 3. Contact with ties within $50 \mathrm{~km}$.

Figure 4. Support with ties within $50 \mathrm{~km}$.
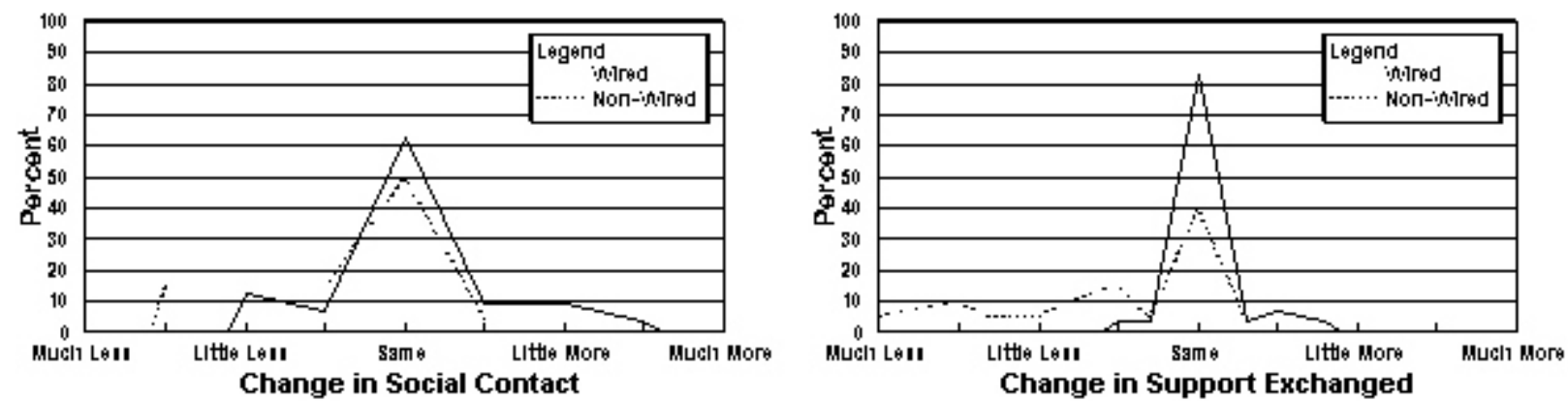

Figure 5. Contact with mid-range ties.
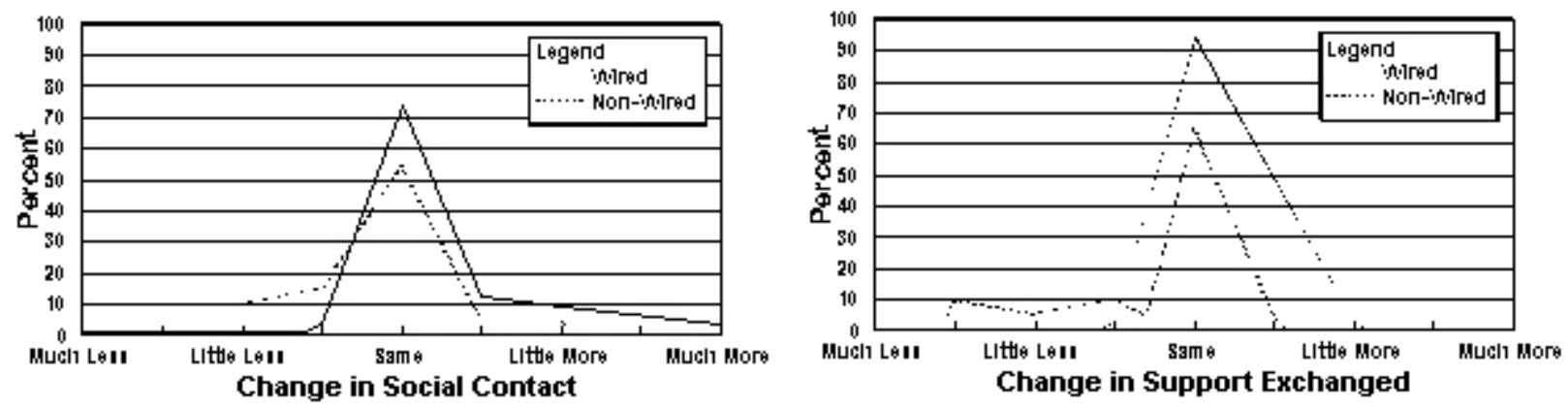

Figure 7. Contact with distant ties $(500 \mathrm{~km}+)$. Figure 8. Support with distant ties $(500 \mathrm{~km}+)$. 